Rau and A. Ananthanarayana Ayer contribute a study at length of South Indian brains, and G. M. Kurulkar studies briefly "The Abdominal Bulge in Health (Males)".

Turning to the non-physical contributions we find a useful essay on "Basic Concepts in Anthropology" by Mandelbaum which has been evoked in part by correspondence resulting from the broadcasting of lectures in anthropology direct from a Minnesota classroom. Clearly the study of anthropology is more popular, or better boosted, in the United States than in Great Britain. Aiyappan writes well on "Theories of Culture Change and Culture Contact", as does Prof. Chattopadhyay on "Conflict and Social Behaviour", though the latter's psychological explanation of why the inhabitants of Bengal accepted Islam more readily than those of the Agra and Oudh only really amounts to the fact that the latter had been Hinduized for a longer time.

One of the best essays in the volume is Mrs. Karve's "Some Studies in the making of a Culture Pattern". She examines the conflict between patrilineal and patrilocal institutions on one hand and matrilocal institutions on the other, and discusses the cross-cousin marriage in Maharastra, and the maternal uncle-niece marriage found farther south. She comes to the conclusion that patriliny is an indigenous institution derived from a primitive hunting-gathering complex; and although one may find difficulty in accepting the theory that it was not an Indogermanic import, one cannot but endorse wholeheartedly her criticism of "the unsoundness of a policy which would impose the same code on the whole of India completely disregarding the cultural and historical antecedents of different provinces and different castes".

All the essays, of course, are not of the same high level. Radhakumud Mookerjee's attempt to show that the Rig.Veda is not later in time than the Indus civilization of 3000 B.c. fails to convince. He argues that the Hittite deities with names analogous to those of India, Mitra and Varuna, must have been carried to Mesopotamia from India, ignoring the more likely hypothesis of a distribution from some common centre in Iran or near the Caspian. He seems to think, moreover, that the Sumerians and "Dravidians" belonged to a common physical type; but whereas the Sumerians, so far as our evidence goes, seem to have been brachycephalic, Dravidian-speaking India is on the whole emphatically dolichocephalic, and his statement that the Rig-Veda "is the earliest text not merely of India but of the world" does not help one to accept his conclusions without reserve.

W. J. Culshaw writes of "The 'Folk Consciousness' of the Santals", and W. G. Archer of "The Women's Hunt", a periodic phenomenon of Oraon culture which impresses itself on neighbouring tribes as a sort of "cross between a pantomime and a carnival". J. P. Mills deals with "Some Recent Contact Problems in the Khasi Hills", making the problems clear enough but not offering a solution; C. Fürer von Haimendorf writes of "Religion and Ethics among the Konyak Nagas and other Indian Tribes" and in doing so qualifies the conclusions he came to in "Custom is King" ; and Elwin writes, informatively again, on "Primitive Ideas of Menstruation and the Climacteric in the East Central Provinces of India". P. G. Shah in "Non-Hindu Elements in the Culture of the Bhils of Gujarat" makes a useful and important contribution to the study of that tribe, the docu- mentation of which has been neglected to an extent out of all proportion to its importance.

The remaining essays-though one seeks in vain, alas, for one by Dr. B. S. Guha-include one on "Bongaism" by D. N. Majumdar, a joint editor who contributes also an introduction giving an account of Sarat Chandra Roy, whose portrait serves as a frontispiece, but is not well reproduced. The volume has an index and is commendably free from misprints. "Essays in Anthropology" is probably the first anthropological Festschrift to appear in India. If subsequent ones keep up to the standard set by it they will do well enough.

\section{FUNCTIONS OF A COMPLEX VARIABLE}

\section{Vorlesungen über allgemeine Funktionentheorie und elliptische Funktionen}

Von Prof. Adolf Hurwitz. Herausgegeben und ergänzt durch einen Abschnitt über Geometrische Funktionen, von Prof. R. Courant. Dritte, vermehrte und verbesserte Auflage. (Published and distributed in the Public Interest with the consent of the Alien Property Custodian.) Photo-lithoprint Reproduction, 1929. Pp. xii +534. (New York: Interscience Publishers, Inc., 1944.) 7.50 dollars.

DERHAPS one of the most regrettable consequences of the War, from a purely academic point of view, has been the inevitable loss of touch with current developments in Europe and the accompanying in. accessibility of standard Continental literature. The appearance of a photo-lithoprint reproduction, from the United States, of one of the classical treatises on function theory, which in pre-war years was rightly regarded as an indispensable possession of the pure mathematician, is thus an event of paramount interest and importance.

This volume, in German, containing among its pages all the fundamental theorems and the results of the classical theory of functions of a complex variable, is so well written as to be almost impervious to any sort of criticism, however fastidious.

It is a third and enlarged edition of the original produced by the authors in 1922 and is divided into three principal sections, of which the first two are mainly ascribable to Hurwitz and the last to Courant.

The first section consists of a development from 'first principles' of the Weierstrassian treatment of the theory, the fundemental idea being the complex power-series and its analytic continuations, from which Cauchy's theorem and its corollaries are ultimately derived. A certain amount of special function theory is also included, with particular reference to integral and meromorphic functions.

The second section, on elliptic functions, gives an account of the elementary properties of doubly. periodic functions, proceeding by way of the Weierstrassian functions and theta functions to those of Jacobi and the elliptic modular function and finally to a discussion of elliptic integrals and their transformations.

The last half of the book, comprising the third section, is entitled "Geometrical Function Theory" and deals very comprehensively with a large variety of topics, including Riemann surfaces, Picard's theorem, conformal representation, Dirichlet's principle, Green's functions and the fundamental theorem of Riemann. 